\title{
The use of the absent and Othering in design and critical analysis of PD activities
}

\author{
Bo Westerlund \\ Konstfack, University College of Arts, Crafts and Design, \\ Stockholm, Sweden \\ bo.westerlund@konstfack.se
}

\begin{abstract}
In this paper I explore the use of the concept representation and argue that it can complement the concept constituting in order to support the design and critical analysis of participatory design activities. John Law acknowledges that in a representation some things are made present, while others are deliberately made absent, which is necessary. But it is important to realise that there are also things that are Othered, i.e. things that are unconsciously repressed and absent. The concepts are explored with the help of two cases involving participatory design workshops. I discuss how both concepts can be used in order to make sense of these participatory design activities. The paper also reflects on the importance of what realities the method used supports to be made present.
\end{abstract}

\section{CCS Concepts}

- Human-centered computing $\rightarrow$ Participatory design

\section{Keywords}

Participatory design; Co-design; Prototype; Critical analysis, Representations;

\section{INTRODUCTION}

\subsection{Background}

In participatory design (PD), users, and other stakeholders, are invited to participate in the design work with the hope that their experience will support the creation of "new" proposals that are better suited for the context in question. But how can we be sure that the proposals are relevant in cases where the situation is not so clearly defined, when it is messy and complex? How can the prototyping as well as the reflection and judgement be supported? PD is sometimes criticised for not taking participation seriously [1, 10], avoiding conflicts, and also for not attending to challenging issues, instead mostly attend to present concerns [3].

In a previous paper, Regarding Design as a Constituting Practice Matters [18], I argue that the concept constituting is often far more relevant than the concept representing in relation to design work. The terms representing and representation are often used to describe the relation a prototype has during design work, to the end result. The prototype is then seen to represent the final product. I suggest that it is "important to see design work as a constituting practice rather than a representative one. Supporting this standpoint are both the fact that the future does not yet exist and therefore is difficult

Permission to make digital or hard copies of all or part of this work for personal or classroom use is granted without fee provided that copies are not made or distributed for profit or commercial advantage and that copies bear this notice and the full citation on the first page. Copyrights for components of this work owned by others than the author(s) must be honored. Abstracting with credit is permitted. To copy otherwise, or republish, to post on servers or to redistribute to lists, requires prior specific permission and/or a fee. Request permissions from Permissions@acm.org.

PDC '16, August 15 - 19, 2016, Aarhus, Denmark

Copyright is held by the owner/author(s). Publication rights licensed to ACM. ACM 978-1-4503-4136-3/16/08 ..\$15.00

DOI: http://dx.doi.org/10.1145/2948076.2948082 to represent, and the strong argument that knowledge is created in dialogue and constituted in action" [18]. This argument mainly builds on John Stewart's semiotic understanding of representation $[15,16]$, one that claims that a representation mirrors "the reality".

Since design work is said to focus on how things ought to be, focussing on the constituting aspects of prototypes encourages an on-going design activity, and refrains from the impression that the proposals come nearer and nearer to a "final solution". Instead, prototyping seen as a constituting activity supports the materializing of different proposals, standpoints and thereby produces several possible realities [9].

\subsection{Representation as seen by John Law}

In this paper I argue for the value of using the concept representation the way John Law presents it in Making a Mess with Method [8] and After Method [9] acknowledging that in representations "some things ... are present but at the same time other things are being rendered absent" [8]. The list is of things that are not made present is of course endless, some of these things are obvious and other things are made absent in order to emphasise what is made present. Law sees no problem in the "exclusion as such ... [but in] the denial of that exclusion" [8]. He calls this Othering. Othering is absence that is not acknowledged, "everything that is being repressed for one reason or another". Further on Law suggests "Everything that doesn't fit the standard package of common-sense realism is being repressed. Everything that is not independent, prior, definite and singular." He claims that, "our research methods work to other that which does not fit a metaphysics of common-sense realism" [8].

I interpret Othering as a concept that can be used to support researchers to be more sensitive when reflecting on, for example prototypes and design proposals. We also need to be sensitive about and acknowledge that people see different aspects as present and absent depending on our experience and other knowledge. One example can be gender aspects that nowadays often are more acknowledged than fifty years ago when they were highly Othered.

\subsection{Representation and methods}

Both Stewart and Law would agree on that most contexts could be seen as messy, and be impossible to describe exhaustively. "Method is not ... a set of procedures for reporting on a given reality. Rather it is performative. It helps to produce realities" [9]. Law emphasises that these produced realities, the representations, present some things that resonate with the messy reality, while other aspects are deliberately made absent, and finally things are also Othered.

Stewart suggests that knowledge is constructed and constituted through conversations. For him the concept representation seems to mean that all aspects of "the reality" are present. So the word "representation" points at two different concepts (at least).

We need ways of knowing messy contexts. Law argues that some activities and contexts are in such complex relations to each other that they can only be known vaguely [8]. With this in mind it is obvious that we need to be careful when designing the inquiry 
to avoid that "everything that doesn't fit the standard package of common-sense realism is being repressed" [8].

As a designer you do not only need ways of knowing the messy realities, but also ways of knowing what to propose, what to design. Design is best known for providing proposals for solutions, but is also acknowledged for creating knowledge about the context of inquiry, which is needed in order to know what should be solved. Schön calls this problem-setting [13] and is seen as an integral aspect of design work, where creating proposals and understanding the problem co-evolve [2]. These should be seen as two inseparable, intertwined activities that co-constitute each other.

PD researchers consider invited and created material important "assisting in staging co-designing and intertwining in mediating discussions and negotiations, and power relations" [e.g. 4]. The approach to, or method for, the PD workshops presented in this paper departs from the participants' own experience and knowledge. The material and format encourages and supports participants to create specific and detailed proposals that are intended to afford desirable realities to be made present. The aim with this particularity is also to support in depth reflections and negotiations.

\section{TWO CASES}

I will now briefly presented and explore two cases. The first one is used in my previous paper that I refer to [18] and the second from an on-going research project. They both deal with messy contexts and the participants co-create proposal intended to represent desired realities by making some things present. The cases help us discuss what is made absent and what might be Othered.

\subsection{Co-design workshop}

The aim with the research project Togetherness remotely (Samhörighet på distans) $[11,17]$ was to construct and install video connections between three workplaces that shared the same work, but were located far apart from each other. We designers wanted to learn about their working environment and practice, as well as explore what the technology could support, where it should be placed, etc. We used several methods to co-create this understanding and video prototyping activities were one of the methods we used. Below is an account of one of the 25 video prototypes [17] created.

The video prototype is called Happy company, without disturbance (Glatt umgänge, utan störning) and begins by showing how difficult it is to work in a call centre when colleagues are talking nearby. This is an account of the current situation; after that the group shows their

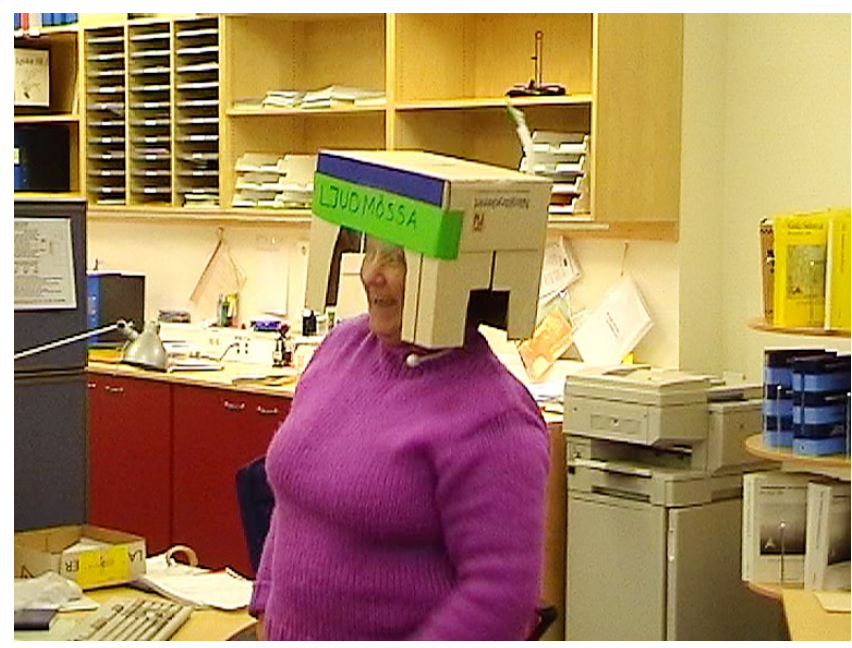

suggestions for interacting with each other in the future without disturbing their colleagues. They need silence when talking on the phone but also want to be able to talk to one another while engaged in other duties, for the sake of relaxation and the many other reasons why workmates want to talk with each other.

The video prototype then shows how two women put on paper boxes used for copying paper and labelled Sound Cap (Ljudmössa). They walk around in the room and seem to be able to talk freely to each other without disturbing their colleagues. [18] (Image 1 and 2).

This video prototype was created by three women and clearly created out of their own experience of the frustrations they did not want to encounter again in the future. The proposal shown in the video is most probably not an acceptable solution if it is seen as a representation of the final system, since not many people would like to go around with cardboard boxes on their heads. But if we use John Law's understanding of representation we could say that the women chose to make present some of the interactions that they would like to be able to experience and preform in their workplace, how they would like to experience the socio-materiality, while they deliberately made absent some of the interactions with the artefacts that should be avoided in the proposed system, like complex log in procedures.

Reasoning with the concepts constituting and present-absent could lead to a quite similar understanding of the video prototype. But the concept of Othering is a radically new contribution to the work of reflecting, of making sense [7] since it challenges us to explore possible issues that are absent but still may be of great importance. If this proposal would be actualized there could be feelings of exclusion from the colleagues that have no possibility to overhear the conversation. Could this technology be used to introduce new performances of power in the workplace? This is not addressed in the video prototype. Aspects of surveillance are not addressed either; can the boss notice who wants to take a break? There can be several issues, aspects and perspectives that are Othered in the video prototype that could endanger a successful implementation.

\subsection{Urban planning co-design workshops}

There is a growing interest in exploring PD in complex planning processes [e.g. 12] both from democratic aspects as well as from hopes of "efficiency". The second case is taken from such a project, Decode, which explores how co-design approaches can contribute to democratisation of official urban planning processes [5].

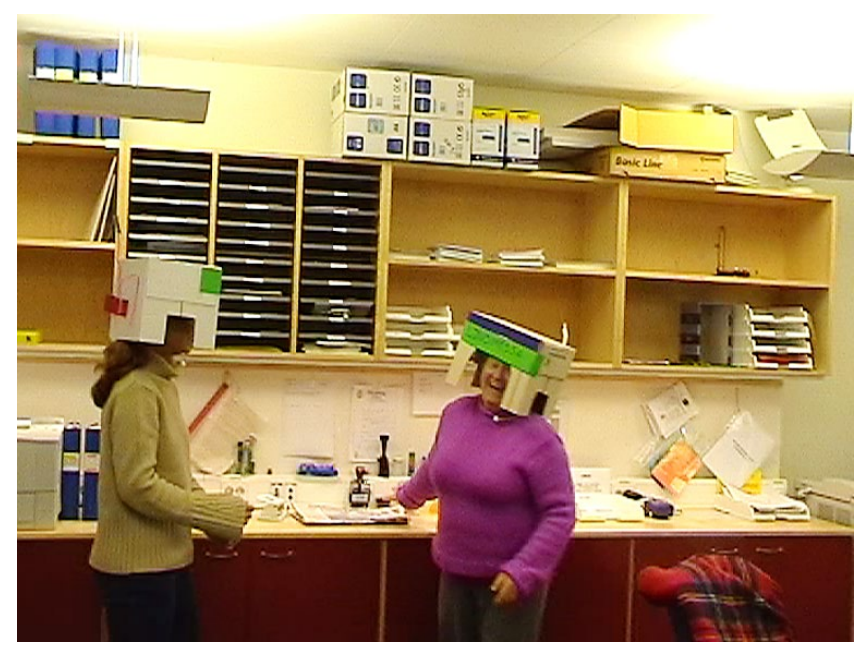

Image 1 and 2. The Sound Caps in the video prototype Happy company aim to enable people to talk freely in the workplace without disturbing their other colleagues. CBo Westerlund 
I took part in creating and conducting two workshops inspired by and exploring an on-going conflict. The conflict concerned the proposal of two new streets with through traffic between apartment buildings that have existed since the 1960's. There is currently no traffic in the area where the streets are planned. 900 citizens had signed a petition protesting against the streets that were suggested by the municipality's planning office and supported by the politicians.

The arguments for and against the streets were made on several "levels", both very abstract and concrete. The citizens were very concrete in their protests. They claimed that the traffic on the streets would be very disturbing for the people living next to them; there would be risk for accidents with pedestrians, cyclists, people with disabilities and children. To make space for the streets over 20 trees need to be chopped down.

The planners, politicians and therefore also the official documents were more abstract arguing the advantages for the area to be city-like (stadsmässig) and have a fine-mesh network of streets (finmaskigt gatunät).

In order to explore this situation with a co-design approach we decided to conduct two co-design workshops $[14,17]$ with the aim to support a creative discussion of possible alternative proposals. We invited citizens, civil servants and politicians to the two workshops. We wanted to create an understanding of the design space, i.e. the multiplicity of possible proposals that would be accepted by enough people. We wanted the participants to stay with their experience, not strive for consensus, but still negotiate, adjust their understanding and respect the other participants experience and opinions [5].

The approach or method was to encourage participants to create proposals, discuss these and to be very particular and precise during the workshop. Therefore we initially asked the participants to present what they currently do in the area, i.e. what they need and want the area to afford [6]. They indicated physically their use of the area by marking with thin tape and signs on an aerial photo and presented orally. This seemed to support many different points of view of the area being present at the same time.

The participants created several reasonable proposals that would afford many people to continue with their current everyday activities. Image 3 presents one proposal, drawn on tracing paper on top of the quite detailed account for the workshop participants' use of the area. One aim was to support negotiations between alternative design proposals co-created by the participants and the proposal made by the community's planning office.

One common-sense understanding of the workshop method would be that the proposal that afforded most activities and constrained the least would be the one implemented, but this is not what happened in this case. After the workshops, the politicians in the municipality decided on a proposal that was quite similar to the initial proposal, the one that many of the citizens protested against. This could mean that the workshop method itself did not enable a relevant representation of the messiness where the most important aspects were made present. One aspect obviously Othered in the co-design method was power; the politicians have the power to actually decide on the actual design of the area, while the citizens participating in the workshop could only produce proposals.

The effort to make the proposals and discussions concrete, and therefore not deal with more abstract values and concepts (e.g. citylike) perhaps Othered the possibility to also negotiate and reflect on some even more important issues, like power. Where there other constraints that we did not deal with in the workshop? What more is Othered? What else could hinder actualising the participants' proposals?

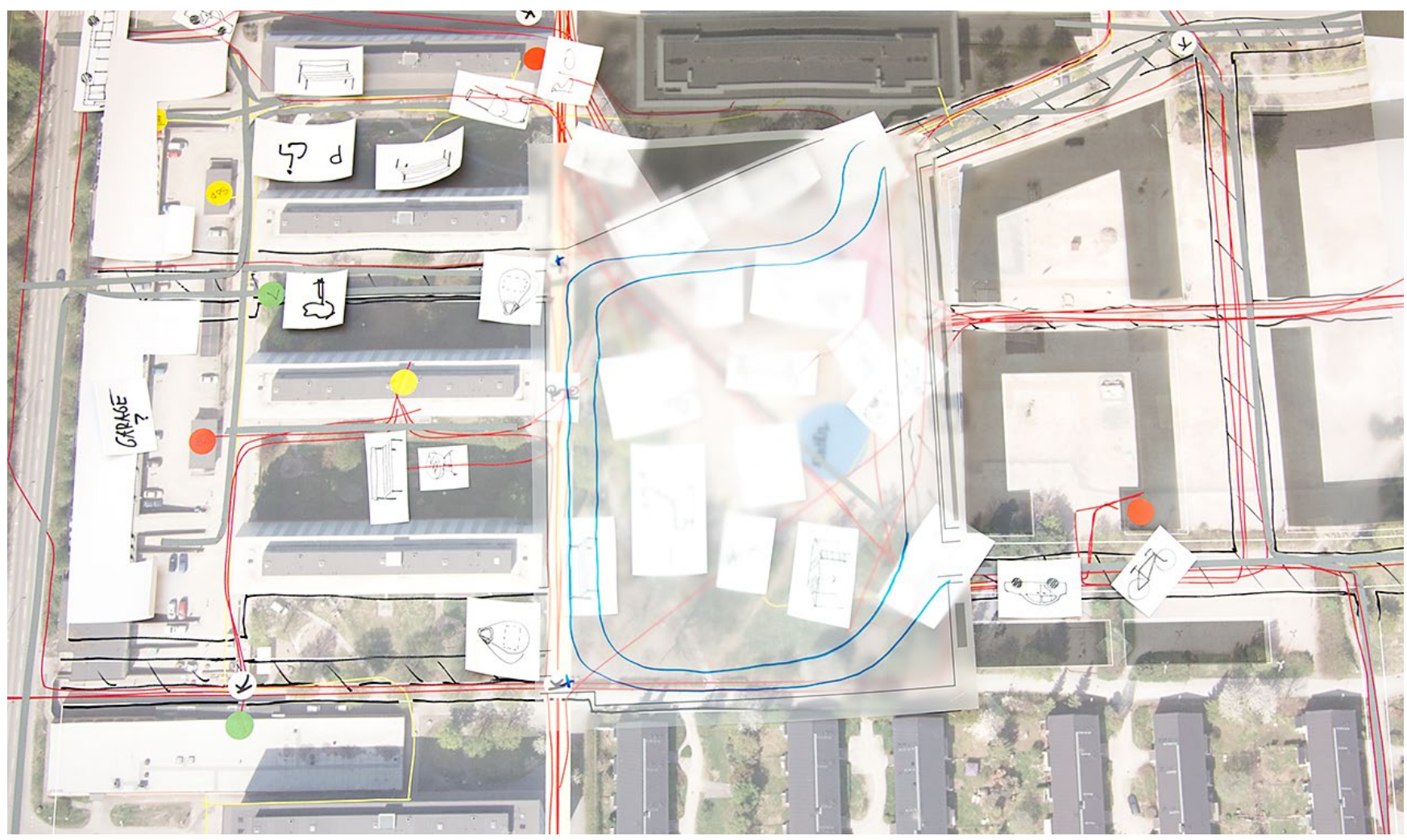

Image 3. This aerial photo was used to indicate, or represent, the current activities done by the participants on the area in question. Here is also one of the alternative proposals for where the street should be located, on tracing paper. $\mathbb{C}$ Bo Westerlund 


\section{DISCUSSION}

In the two cases presented, the use of material is important in the proposals (for example the Sound Cap prototypes, and placements of streets on tracing paper) and supports making the representations quite detailed and specific, despite the messiness of the contexts. This is a result of the formats or methods of the workshops. These accounts are detailed and particular, and make present issues that some of the participants consider important. The workshop method seems to support Law's suggestion to embrace the messiness by presenting multiplicities, indefiniteness, undecidabilities, and "holding them together" [8] through this range of proposals that constitute parts of the design space. Here participants can create proposals, as well as critique and negotiate among the diverse range of proposals. This supports the aim of creating a better understanding of the design space [17].

All methods support some aspects and perspectives to be made present while some are made absent. In order to enable careful design of explorations and critical analysis of the results concerning for example power in participatory design processes, the Othered must be acknowledged in order to be reflected on. We need to design inquiries in ways that encourage making present issues that produce realities where conflicts, difficulties, arguments, disagreements and other crucial aspects in order to be able to address these.

We must challenge our common-sense realism [8] and being aware of Law's use of the concept Othering is one contribution to better design of participatory design activities. If the prototypes are allowed to embrace complexity and diversity and represent contradicting standpoints there is a fair chance that these prototypes can materialise aspects that support reflecting on what might be Othered.

Othering is a concept that can be used to support researchers to be more sensitive when reflecting on, for example, prototypes and design proposals. What is experienced as Othered by one person does not have to be the same as what someone else experiences, depending on different experience and knowledge. Idealy reflections on proposals are made together with the stakeholders since the collective experience and knowledge will support more diverse reflections. During the workshop where Happy company was created no one acknowledged that this could lead to anything unwanted. This was done afterwards. But in the public planning case most participants were highly aware of which of the participants who had power outside of the workshop setting, although power was not an aspect that was present in the format of the workshop.

Looking back at the two cases it seems as if the method or format for the first workshop afforded the creation of a proposal that has a relevant amount of aspects made present and absent, and not so much Othered. While the proposal from the second workshop has aspects made present that are very relevant for the participants, other aspects that are crucial for the implementation are Othered.

Reflecting on Kees Dorst's view on design as a co-evolution between providing proposals for solutions and problem-setting [2], we can see that the concept constituting can be used for reflecting on the results from for example a workshop (e.g. prototypes) in terms of proposals. The prototypes created could be seen as constituted statements in an on-going "conversation", a sociomaterial conversation. While the concept representation [8] can be used to reflect on what knowledge this prototype presents regarding the puzzling situation; i.e. how well the problematic issues are represented. The emphasis needs to be expanded to also consider the absent, and especially the Othered.

\section{ACKNOWLEDGEMENTS}

I gratefully thank all participants for their engagement and contributions, as well as Maja Frögård and the other researchers involved in both projects, without whom this research could not have been conducted. I also thank the great anonymous reviewers for their thorough, critical and constructive feedback on previous versions of this paper. Decode was partly funded by VINNOVA.

\section{REFERENCES}

[1] Cooke, B. \& U. Kothari (eds) (2001), Participation: the new tyranny? Zed Books: London.

[2] Dorst, K. and N. Cross (2001) Creativity in the design process: Co-evolution of problem-solution. Design Studies 22. doi:10.1016/S0142-694X(01)00009-6

[3] Edeholt, H. and H. Nsaiszeka Mainsah (2014) Glocal Participatory Design - designerly approachesd for translocal climate change initiatives, Proceedings of PDC 2014. doi $>10.1145 / 2662155.2662186$

[4] Eriksen, M., E. Brandt, T. Mattelmäki and K. Vaajakallio (2014) Taking Design Games Seriously, Re-connecting Situated Power Relations of People and Materials, in Proceedings of PDC 2014. doi $>10.1145 / 2661435.2661447$

[5] Frögård, M. (2016) Negotiating matters - perspectives, material and format supporting agonistic pluralism in community planning, in ServDes2016 Geographies, Proceedings of the fifth Service Design and Innovation Conference: Copenhagen.

[6] Gibson, J.(1979)The Ecological Approachto VisualPerception, Boston: Houghton Mifflin.

[7] Krippendorff, K. (2006) The Semantic Turn, BocaRaton, FL: Taylor \& Francis.

[8] Law, J. (2003) 'Making a Mess with Method, the Centre for Science Studies: Lancaster University, Lancaster.

[9] Law, J. (2004) After Method, Mess in social science research, London: Routledge.

[10] Miessen, M. (2010). The nightmare of participation: [(crossbench practice as a mode of criticality)]. New York, Berlin: Sternberg Press.

[11] Räsänen, M., B. Thuresson \& A. Wiberg (2005) Samhörighet på distans, Technical report CID/KTH, Stockholm, CID 325, http://cid.nada.kth.se/publikationer/rapporter.html (accessed 2016.05.23)

[12] Salgado, M. and M. Galanakis (2014) “... so what?”-Limitations of Participatory Design on Decision-making in Urban Planning, in Proceedings of PDC 2014. doi $>10.1145 / 2662155.2662177$

[13] Schön, D. (1983) The Reflective Practitioner: How Professionals Think in Action. New York: Basic Books

[14] Steen, M. (2014) Co-Design as a Process of Joint Inquiry and Imagination, Design Issues, Volume 29, Issue 2, p16-28.

[15] Stewart, J. (1995) Language as Articulate Contact: Toward a Post-Semiotic Philosophy of Communication, New York: SUNY Press.

[16] Stewart, J. (Ed.) (1996) Beyond the Symbol Model: Reflections on the Representational Nature of Language, New York: SUNY Press.

[17] Westerlund, B. (2009) Design Space Exploration, co-operative creation of proposals for desired interactions with future artefacts, Doctoral thesis. Stockholm: KTH.

[18] Westerlund, B. (2011) Regarding Design as a Constituting Practice Matters, In Proceedings of the Nordic Design Research Conference: 'Making Design Matter', Helsinki: NORDES. pp 308-311. http://www.nordes.org 